Paidéia, 2006, 16(33), 81-90

\title{
PRÁTICAS EDUCATIVAS FAMILIARES E O SENTIDO DA CONSTITUIÇÃO IDENTITÁRIA ${ }^{1}$
}

\author{
Heloisa Szymanski ${ }^{2}$ \\ Pontifícia Universidade Católica de São Paulo
}

\begin{abstract}
Resumo: O estudo aqui relatado teve por finalidade investigar o sentido de práticas educativas implementadas por pais moradores de um bairro de baixa renda em São Paulo e analisá-las como parte do processo de constituição identitária. Tais práticas se revelam como ações através das quais se desenvolve o processo de socialização familiar, refletem uma visão particular de mundo e de homem, situam-se num contexto histórico e de classe social e contribuem para o processo de constituição identitária. Trata-se de pesquisa qualitativa de base fenomenológica que teve como procedimento a realização de entrevistas e atividades grupais com famílias. Os resultados revelaram que o sentido socializador das práticas dirigia-se para formar pessoas dóceis à ordem autoritária, recorrendo-se a práticas disciplinares violentas, configurando um contexto voltado para o evitar uma identidade "negativa".
\end{abstract}

Palavras-chave: família e práticas educativas; família e identidade; práticas educativas violentas e identidade negativa.

\section{FAMILY EDUCATIONAL PRACTICES AND THE MEANING OF IDENTITY CONSTRUCTION}

\begin{abstract}
This investigation aimed to understand the sense of family educational practices developed by parents of a low income neighborhood in São Paulo, Brazil, and to analyze those practices as part of the process of identity construction. Educational practices are shown as actions through which the process of socialization in the family is developed; they contribute for personal identity construction and reflect a man's and world's view, in a historical and social class context . It was a qualitative phenomenological research and its data were collected through interviews and group activities with families. Results indicated that the socializing sense of their family practices was directed to rear docile people, obedient to an authoritarian order, subjected to violent disciplinary practices that provided a context directed to the avoidance of a "negative" identity.
\end{abstract}

Key words: family and educational practices; family and identity; violent family practices and negative identity.

Introdução: Este estudo visou investigar o sentido de práticas educativas implementadas por pais moradores de um bairro de baixa renda em São Paulo, buscando analisá-las como parte do processo de constituição identitária, considerando-se as práticas educativas familiares como sendo:

“... ações contínuas e habituais, realizadas pelos membros mais velhos da família, nas trocas intersubjetivas, com o sentido

\footnotetext{
${ }^{1}$ Artigo recebido em 14/02/2006 e aceito para publicação em 09/06/ 2006

${ }^{2}$ Endereço para correspondência: Heloisa Szymanski, Rua Maranhão, 531, apto 52, São Paulo - SP, CEP: 01240-001, E-mail: hszymans@pucsp.br
}

de possibilitar a construção e apropriação de saberes, práticas e hábitos sociais pelos mais jovens, trazendo, em seu interior, uma compreensão e uma proposta de ser-no-mundo com o outro" (Szymanski, 2001 p. 87)

Tais práticas concretizam-se em ações que revelam o modo como são socializados os membros jovens da família, que comportam momentos fundamentais para a constituição identitária, que se refere a um processo relacional, elaborado reflexivamente em meio a trocas intersubjetivas, situado social e historicamente, com uma orientação valorativa e afetiva, referindo-se à experiência individual ou coletiva de 


\section{Heloisa Szymanski}

ser si-mesmo ou de pertencer a um grupo social e com a possibilidade de transformação ao longo da existência (Ricoeur, 1991; Cohen, (1995); Giddens, 1991 \& Bruner, 1997). Observa-se que essa concepção de processo identitário enfatiza a influência mútua entre as pessoas, despertando sentimentos, avaliações e interpretações acerca de si mesmas, do outro e do mundo em que vivem.

As práticas educativas podem revelar inúmeros sentidos conforme os pais ou os cuidadores compreendem sua condição socializadora e interpretam as reações dos filhos expressas verbal e não verbalmente. A nova geração responde aos cuidados também movida por sentidos os mais diversos, a partir da compreensão que estruturam em relação a si, ao outro e ao mundo familiar.

Para Berger e Luckmann (2004), ao considerarem o agir social, sentido é visto como "nada mais do que uma forma complexa de consciência: não existe em si, mas sempre possui um objeto de referência. Sentido é a consciência de que existe uma relação entre as experiências.” (p. 15) ... “ O sentido do agir atual é prospectivo, contudo a ação realizada é retrospectivamente significativa. O agir é orientado no sentido de um objetivo pré-projetado". (p. 16). Os autores mostram no que chamam de complexa estrutura de sentido, a existência da antecipação de um estado futuro - no caso desta pesquisa, a pessoa a ser formada pela família - e uma avaliação(p.17), nesta investigação representada pelas justificativas da escolha de uma determinada prática.

As atividades do dia-a-dia são vividas conforme o que Heidegger (1981) chama de solicitude compreendida numa perspectiva fenomenológica existencial como o modo humano de coexistir. A solicitude, também chamada de cuidado, pode ser tanto orientada pela consideração, respeito, paciência, tolerância e esperança, quanto vivida no modo que Heidegger (1988) chama de impróprio ou deficiente, no dia a dia, entretanto, "A convivência cotidiana mantém-se entre os dois extremos da preocupação - a substituição dominadora e a anteposição liberadora - mostrando-se inúmeras forma mistas"(p.173-174).
Escolhe-se de quem cuidar e como cuidar. Formar uma família e ter filhos são opções. Como se cuida de ser mãe ou pai é também uma escolha. Ter filhos e ser cuidador são escolhas culturais, com normas, expectativas e valores já agregados no âmbito da significação. Assim, por exemplo, como se cuida de ser pai? Pode ser providenciando acolhimento afetivo e material aos filhos, ensinando-lhes hábitos e habilidades sociais, possibilitando acesso à educação. Este é, de forma super simplificada, um exemplo do âmbito do significado de ser pai em nossa cultura. Mas também pode ser na forma da negligência, dos maus tratos, do autoritarismo.

Além da consideração de quem se cuida e como se cuida, há um terceiro âmbito: o modo de cuidar, que remete ao sentido e refere-se às disposições, aos estados de ânimo ao se viver a experiência de cuidado. Pode-se cuidar dos filhos pacientemente, esperançosamente, com receio, confiantemente, com medo, como um fardo, meramente repetindo a tradição ou ousando mudar, de forma autoritária, inculcando-lhe medos, ameaçando-o ou enfatizando a autonomia, o amor, a reflexão. As disposições afetivas no desempenho das funções paternas e maternas, por meio das práticas educativas, têm um sentido, que será percebido pelo filho e revelam a maneira como este é visto e expectativas em relação a ele. Por outro lado, o modo como ele percebe as disposições afetivas dos pais terá impacto na sua constituição identitária, já que esta é um processo relacional.

Essa perspectiva é fértil para a consideração de práticas educativas, pois estas implicam a transmissão de sentidos na constituição de si mesmo, na compreensão do mundo e dos outros. Viver em família remete a um modo de se tratar mutuamente, de cuidar de cada um e da própria vida familiar, carregado de afetividade, com sentido nem sempre explicitado e sob o peso de tradições passadas de geração em geração.

Práticas educativas consideradas como uma forma de cuidar da relação e que expressam o modo de ser do adulto com a criança refletem diferentes interpretações da tarefa socializadora, delineiam expectativas e definem atitudes. Estas últimas, ao se referirem às crianças e a seus pais, direcionam forte- 
mente as práticas escolhidas. Daggett, O’Brien, Zanolli e Peyton (2000) apontam mães com experiência de pais violentos que, com atitudes negativas em relação a sua própria vida e infância, também tendiam a tê-las em relação aos filhos, levando-as a ações controladoras, agressivas e até mesmo hostis.

Em linha com essas observações, Bugental, Ellerson, Rainey, Lin e Kokotovic (2002) verificaram diminuição de práticas violentas de pais que eram orientados a deixarem de lado atribuições negativas quanto aos comportamentos de seus filhos pequenos e para desenvolverem habilidades de solução de problemas.

Diferentes interpretações das ações desenvolvidas no exercício das funções paternas e maternas baseiam-se em valores e crenças, a fim de explicar ou justificar as escolhas disciplinares. Fortin, Chamberland e Lachance (2000) apresentam um estudo sobre as justificações da violência dos pais como um fator de risco para a criança. Uma delas referese à responsa-bilização do filho pelos atos violentos dos pais. Para esses autores, crenças, atitudes e explicações igualmente servem para legitimar condutas abusivas.

As expectativas dos pais em relação às competências sociais das crianças definem práticas e, conseqüentemente, resultados no seu modo do agir social. Em seu estudo sobre práticas educativas, expectativas dos pais e estilo de socialização de crianças, Bernard-Peyron e Allès-Jardel (2002) observaram uma relação entre esses estilos e as expectativas dos pais quanto aos filhos: “As práticas educativas flexíveis e as expectativas sociais engendram um perfil pró-social, enquanto as expectativas mal delineadas engendram na criança um perfil de oposição ou de isolamento" (p. 20). As crenças e a organização significativa do ato de educar são, pois, eixos poderosos, definidores das ações que se implementarão na família.

Não se pode desconsiderar a influência de fatores usualmente associados a grupos de baixa renda, em especial no que diz respeito à escolaridade dos pais na definição de práticas educativas com os filhos. Muitos estudos (Bernard-Peyron \& AllèsJardel, 2002; Black \& Krishnakumar, 1998; McLoyd, 1990, 1998, Nunes, 1994), têm como ponto comum a constatação de que famílias de baixa renda e baixo nível de escolaridade adotam, com freqüência significativamente maior, práticas educativas violentas com suas crianças, o que se associa a danos para seu desenvolvimento social, emocional e cognitivo. Isto não quer dizer que não se encontrem pais com excelentes habilidades educativas nos meios socioeconômicos menos favorecidos como o contrário, pais de alto nível socioeconômico com dificuldades na educação de seus filhos, como lembra Bouchard (1988). Tornaria, Vandemeulebroeke e Colpin (2001) resumem as considerações acima, ao apontar o duplo aspecto conduta-significado como central ao conceito de educação familiar.

Os comportamentos educativos dos pais têm sido classificados considerando-se várias perspectivas: distribuição do poder entre eles e o filho e a comunicação (Bouchard, 1988); modos de controle, formas de estruturação (Bernard-Peyron \& Allès-Jardel, 2002) e implementação de regras (Durning, 1999). De forma geral, porém, os estudos situam os estilos educativos familiares no eixo democrático, autocrático ou "laissez faire", segundo o grau de rigidez, flexibilidade e coerência da conduta dos pais.

De acordo com a proposta de Paulo Freire a respeito da ação educativa (1970, 1994,1996), podese identificar a postura dos pais com os filhos, assim como a de professores no ensino formal, no eixo dialógico/autoritário. Segundo a análise que Freire (1970) apresenta da prática autoritária na escola, o referencial para a ação educativa é o mundo adulto; pressupõe-se que todo o saber pertence ao adulto, sem muita escuta das urgências e opções dos educandos e desconsiderando a experiência da criança e do adolescente, de quem se espera que se adaptem e se ajustem. O medo subjacente ao pai/ mãe/ é o de que, dando voz aos filhos, haja a perda da autoridade, justificando a violência, física ou não, em nome do ajustamento.

A práxis dialógica tem como atitudes características a horizontalidade - igualdade de valor - respeito e escuta às urgências dos filhos/educandos, sem desconsiderar as próprias, o que remete à solicitude autêntica. Essa proposta aproxima-se do que Bouissou (2001) afirma: 
"Os valores que orientam as práticas educativas e que se pretende transmitir às crianças concernem essencialmente à autonomia, à responsabilidade, à realização pessoal, ao cuidado de si e do outro, à singularidade e à expressividade”(p.44).

O objetivo deste estudo foi o de verificar quais sentidos se delineavam a partir da análise de práticas educativas adotadas por famílias moradoras num bairro da periferia de São Paulo, visando descrever como esses poderiam se relacionar com o processo de constituição identitária.

\section{Método}

Este estudo pode ser definido como uma pesquisa-ação (Chambers,1997; Freire,1980, 1981, Thiollent, 1992) que, segundo Dubost (1988), ressalvando sua "elasticidade" e a grande variedade de formas que assume, pode ser definida como “ uma ação deliberada, visando a uma mudança no mundo real, engajada numa escala restrita, englobada por um projeto mais geral e submetendo-se a certas disciplinas para obter os efeitos de conhecimento e/ou de sentido" (p.45). Para tanto, há a exigência de se escolherem instrumentos de coleta e devolução de dados que preservem a função conscientizadora e mobilizadora da pesquisa intervenção.

\section{Participantes}

Na primeira parte da pesquisa, foram realizadas entrevistas individuais com seis famílias indicadas ${ }^{1}$ por educadoras da creche freqüentada por seus filhos. Participaram as mães, pois nenhum pai se dispôs a colaborar. Das seis famílias, cinco eram nucleares, sendo três delas reconstituídas (segundo casamento da mãe, segundo casamento do pai e segundo casamento de ambos, com os filhos dos casamentos anteriores) e uma extensa (mãe solteira morando com a própria mãe). O número de filhos variou de dois a cinco, as idades, de 1 mês a 11 anos. A idade média das mães era de 24,8 anos e

\footnotetext{
${ }^{1}$ Por razão de segurança dos pesquisadores, alunos de pós graduação da Pontifícia Universidade Católica de São Paulo, os dirigentes da creche preferiram agendar as visitas previamente com as famílias dispostas a participarem da pesquisa, uma vez que aquele é um bairro conhecido como violento.
}

a dos pais 26.1 anos; sua instrução equivalia ao nível fundamental incompleto.

$\mathrm{Na}$ fase da atividade grupal e entrevista coletiva participaram 19 mães, dois pais e 12 crianças de seis a 12 anos. A idade média das mães era 29,3 anos e dos pais 26,6 . Treze mães (68\%) representavam famílias nucleares, das quais 7 (58\%) eram reconstituídas, 2 monoparentais (11\%) e 4 compostas por mães solteiras vivendo com a família de origem (21\%). Apenas três das participantes da primeira fase estavam presentes à reunião final.

Esta investigação incorporou dois tipos de coleta de dados: num primeiro momento, entrevista reflexiva (Szymanski, 2002) com as famílias e, depois, uma entrevista coletiva. O modelo de intervenção utilizado caracterizou-se por seu caráter reflexivo, que parte da constatação de que a interlocução face a face é fundamentalmente uma situação de interação humana, em que estão em jogo as percepções do outro e de si, expectativas, sentimentos, preconceitos e interpretações dos protagonistas: entrevistador e entrevistado.

Holstein e Gubrium (1995) apontam para o caráter ativo dos que participam da entrevista e enfatizam que "o processo de produção de significado é tão importante para pesquisa social quanto o significado que está sendo produzido” (p.4).

$\mathrm{Na}$ fase de aquecimento da entrevista familiar, solicitou-se que as mães ${ }^{2}$ descrevessem cada um de seus filhos, para, em seguida, questionar como lidavam com eles no dia a dia e como agiam quando eles faziam coisas que elas não aprovavam. No decorrer da entrevista investigavam-se as expectativas em relação ao futuro dos filhos, as razões da escolha das condutas educativas e como elas se incorporavam no dia a dia familiar. As entrevistas foram gravadas e transcritas.

A devolução dos dados obtidos deu-se num encontro coletivo, em que no aquecimento propôsse uma atividade de grupo - um tipo de jogo de bingo - tendo como cartelas fotos que representavam situações do cotidiano citadas no primeiro momento da investigação, compondo oito quadros, com fotos de personagens semelhantes aos moradores do bairro em que se realizava a pesquisa, representando

\footnotetext{
${ }^{2}$ Nenhum pai se dispôs a participar.
} 
situações do dia a dia citadas pelas famílias que participaram das entrevistas individuais: criança mexendo numa gaveta, criança fazendo lição, menina com mãe ajudando a pentear o cabelo da irmã, criança não querendo tomar banho, crianças brincando na rua com a presença de mães, crianças brigando na rua, meninos "pegando rabeira de caminhão”.

Depois do jogo, em que cada quadro era descrito, os participantes foram divididos em pequenos grupos, solicitando-se que expressassem suas opiniões sobre as fotos. Ao final da reunião, em um grupo único, com todos os participantes, compararam-se os dados das entrevistas com as respostas elaboradas no grupo. As crianças mais velhas presentes à reunião contribuíram, confirmando, e algumas vezes modificando informações dadas pelos pais. A discussão dos resultados com os participantes caracterizou o momento reflexivo da pesquisa, pois visou apresentar e ponderar sobre a compreensão de todos, pesquisadores e participantes, acerca do fenômeno estudado e provocar um processo de reflexão sobre os resultados. A reunião também foi filmada e transcrita.

\section{Resultados e Análise}

Os dados das entrevistas com as mães e do encontro coletivo foram analisados com base em procedimentos da abordagem fenomenológica (Szymanski, 2004). Em um primeiro momento, depois das transcrições, foram identificadas no texto as unidades de significado, entendidas como aquilo que Giorgi (1985,p.3) chama de trabalho “intradescritivo". A seguir, esses dados sofreram as primeiras aglutinações, constituindo constelações (Szymanski, 2004) em graus crescentes de abrangência, seguindo-se o critério de nelas incluir as unidades de significado que tinham aspectos em comum.

As constelações foram arranjadas até que se delineou uma síntese, organizando os dados em torno das que se chamou de constelações centrais ${ }^{3}$, e que foram submetidas a uma análise do sentido, com a

\footnotetext{
${ }^{3}$ Essa denominação inspirou-se em Glaser e Strauss (1967) . Embora haja semelhanças, o procedimento de análise aqui apresentado é diferente do da "Grounded Theory" apresentada por esses autores.
}

finalidade de se compreender o fenômeno da constituição identitária na família. Tomou-se de empréstimo a noção de "sentido de ser" utilizada por Critelli (1996), entendida como "modo de cuidar dos modos de se cuidar da vida” (p.120). Investigou-se o sentido a partir das interrogações: sendo as práticas ações de cuidado, como este é realizado considerando que é crucial para a constituição identitária das crianças? Que rumos toma esse cuidado? Que possibilidades descortinam-se como contexto de constituição identitária?

Duas grandes constelações finais serviram de base para a análise do sentido e englobam todos os arranjos e rearranjos realizados: "O cuidar: vivência da socialização" e "O cuidado do cuidado: bases afetivas e morais da socialização".

Na constelação "O cuidar: vivência da socialização”, foram incluídos os agrupamentos que se referiam às interações e trocas interpessoais entre adultos cuidadores e as crianças, o exercício da autoridade no desempenho da tarefa educativa e a vizinhança.

As trocas interpessoais apareceram como acolhimento, proteção, educação e disciplina. Chamouse de "acolhimento" a todas as ações que envolviam o usufruir a presença da criança. Incluíram-se situações como fazer companhia, brincar com a criança, participar de momentos de lazer: "Ele (o pai) faz bagunça, ele sai com as crianças, vai fazer feira com a crianças, então eu não tenho o que reclamar dele". As trocas que foram aglutinadas como "proteção" envolviam atividades de cuidados com a higiene, aparência, saúde e alimentação saudável para as crianças. "Educação" englobou tanto atividades como o acompanhamento das tarefas e freqüência das crianças à escola”, como ações de ensinar/educar de cunho preventivo: "Estuda prá você bater o computador, trabalhar na computação... prá você ser alguém na vida, ter seu dinheirinho”.

As trocas agrupadas em "disciplina” envolveram as respostas dos adultos às transgressões das crianças. As reações dos pais ou cuidadores, em princípio, deveriam seguir uma evolução gradual, tendo na "conversa”, também chamada de "diálogo", o ponto de partida para a ação disciplinar. Esta, de fato, resumia-se em repetir a regra e exigir obediência: 


\section{Heloisa Szymanski}

"Bom, eu primeiro dou o primeiro alerta, eu digo: 'Pára com isso'. No segundo, eu torno a falar: 'Pára com isso' No terceiro eu dou uma palmada.” Os passos seguintes incluíam de gritos aos castigos (tirar algo de que a criança gosta, obrigá-la a ficar sentada durante horas, ou a fazer tarefas domésticas). E a punição física: "Peraí que eu vou pegar a taca e você vai falar a verdade. "As vezes eu dou umas correiadas nela, porque a gente educa”. A seqüência da conversa, ameaça até a punição nem sempre acontecia na prática, pois, conforme o estado de ânimo, do grito à punição física, o tempo era mínimo. Incluíram-se aqui também os modos prioritários de se garantir a obediência: ameaçar, amedrontar (invocando o temor ao pai e a Deus), intimidar e efetivar a punição física.

No exercício da autoridade, os adultos seguiam algumas diretrizes e regras que se referiam prioritariamente a sua conduta: serem firmes e coerentes diante das tentativas de transgressão por parte da criança - o que nem sempre era seguido, dependendo do grau de impaciência ou de cansaço físico dos pais e de seu estado emocional: “....agora que eu estou grávida, eles pastam na minha mão”. O bater não poderia ser indiscriminado: deveria acontecer com cuidado, atenção, coerência (sempre que houvesse a transgressão), sem raiva, diferentemente do espancar: "Não bater nas costas, não bater no rosto, não dar murro de mão fechada... basta dar uma cintada. Bater com a mão, relaxa”. Reconheceu-se a diferença entre ações decorrentes da exasperação do adulto com a desobediência da criança e as disciplinares, o que nem sempre acontecia na prática, na qual essa "isenção” não se dava, sendo, assim, uma diferença teórica. Embora minoritários, houve relatos que excluíam a punição física como medida disciplinar: "Chamava ele... não batia, colocava de castigo". Desses pais surgiu a regra de evitar modos agressivos com os filhos como uma forma de prevenir comportamentos agressivos nas crianças.

Entre as regras que visavam ao controle de sua formação moral, estava a verificação da origem dos objetos trazidos por ela e não lhe dar dinheiro: "Se a gente chegava com qualquer coisa, um lápis, ela (a mãe) ia lá na escola perguntar se a professora deu. Eu vou educar do jeito que minha mãe educou”.

As regras a que as crianças deveriam obedecer referiam-se principalmente ao modo de ser com os adultos : obediência, não intervir em suas conversas, não incomodar: "Eu digo senta, pára, fica quietinha no seu canto quando a gente estiver conversando”. Diziam também respeito à linguagem, evitar palavrões; falar a verdade; preservar a intimidade familiar, não contando segredos familiares; respeitar a propriedade alheia, não se aproximar, nem tocar, sem permissão, objetos de outras pessoas, e à integridade física dos demais, não bater nos colegas e irmãos. O esperado era submissão às regras: "Queria que eles obedecessem mais”, observandose a predominância de um modo autoritário de fazer valer as normas morais.

A vizinhança como ambiente socializador apareceu com duas conotações diferentes, até opostas. Por um lado, a rua representava perigo, más companhias, oportunidade de promover comportamentos indesejáveis, como brigar e roubar, assim como vulnerabilidade diante do tráfico de drogas. Por outro, também exercia papel controlador, em especial na adoção de práticas violentas. Há depoimento de uma mãe que precisou fingir bater no filho, com um ramo de árvore, para mostrar aos vizinhos que o estava "educando". A rua seria lugar de socialização, desde que "a porta de casa esteja aberta" sob a vigilância da mãe.

A outra constelação central é "O cuidado do cuidado: bases afetivas e morais da socialização”. Nessa incluíram-se agrupamentos que se referiam aos filhos e ao futuro, valores, orientadores e explicações/ justificativas das práticas adotadas e estados de ânimo dos pais/cuidadores ao longo da implementação das ações educativas.

No agrupamento referente aos filhos e futuro incluíram-se as suas características consideradas positivas e negativas, as ações desejáveis e as que deveriam ser erradicadas ou prevenidas, assim como os desejos e idealizações de qualidades almejadas para as crianças e jovens, as expectativas pessoais, profissionais e educacionais em relação a eles. Os traços mais citados referiam-se ao temperamento das

\footnotetext{
${ }^{4}$ Todos os nomes são fictícios.
} 
crianças e polarizaram-se em: amorosidade, obediência, teimosia e agressividade. "A mais amorosa é a Daiane ${ }^{4}$. Ela chega da creche e só quer eu”; “A Érica é obediente, mas briga muito...ela é briguenta demais a Érica"; "Ele é arteiro, gosta de bater nos irmãos, judia mesmo dos irmãos".

O item descritivo mais lembrado foi a disposição em ajudar nas tarefas domésticas, especialmente as meninas, seguido de companheirismo com a mãe e disposição em defendê-la da agressividade do pai, quando fosse o caso. Também constituíram-se em itens descritivos, embora menos citados, características morais e inteligência/esperteza.

Entre as ações das crianças consideradas desejáveis, destaca-se o tratamento respeitoso aos pais e aos mais velhos, seguidas de atividades de colaboração nos trabalhos domésticos: “Tipo assim: de manhã ela (Tati, de sete anos) olha o Jackson (6 meses) para mim lavar roupa. Daí fico com ele e ela vai brincar. Aí mais tarde ela faz ele dormir e eu acabo de arrumar a casa”. São também lembradas como ações desejáveis a realização de tarefas escolares, aceitar as rotinas (comer, tomar banho e dormir na hora certa) e o brincar.

Entre as ações tidas como indesejáveis aparece, em primeiro lugar, a desobediência (teimosia, oposição) às ordens dos pais referentes às rotinas de higiene, alimentação, horários de dormir e no que diz respeito à segurança (ir para a rua): "Porque aqui é um lugar que a gente não pode criar filho solto, né?”. Também enfatizaram a agressividade dentro e fora de casa e as transgressões às normas morais, em especial a mentira e o roubo.

Quanto ao desejo de mudança em relação ao modo de ser dos filhos, aparece a melhora de seu comportamento no sentido de maior obediência, a esperança de abandono de atitudes perturbadoras da ordem doméstica como "ser pirracento", "briguento", “teimoso”, "agitado”, "agressivo”. O filho “ideal” seria o que aceitasse incondicionalmente a autoridade dos pais, além de mostrar afetividade e disponibilidade para ajudar.

As expectativas profissionais não se fixam em profissões específicas, mas em se preparar para o trabalho, para ter "sua vidinha”, seu futuro, "ser al- guém”; não almejam atividades reservadas às elites: "trabalhando não no nível alto, mas num estado bem"; consideram tanto a escolha de cada um ("mas vocês têm que seguir a carreira que vocês quer"), como dirigi-los para um determinado ramo de atividade: “Computador. Hoje em dia o mundo gira em volta do computador, essas coisas assim que tá surgindo, né? Prá todos eu pretendo fazer isso".Nenhuma família mostrou expectativa de que os filhos cursassem universidade; o segundo grau já seria um grande avanço em relação à própria escolaridade. A expectativa pessoal prioritária em relação aos filhos era que evitassem qualquer comportamento que os levasse, futuramente, a roubar; esperavam que sobrevivessem à violência e escapassem à cooptação do tráfico: "Quando é assim, eu pego e bato, porque é melhor eu bater do que mais tarde eu chorar, né?”; "se falar mentira, apanha, porque quem mente rouba"; "não admito mexer em coisas dos outros, cria hábito".

Foi possível identificar alguns princípios que dirigiam as práticas. O respeito aos mais velhos constituiu-se como a base. Falar a verdade apareceu associada à consideração pela propriedade alheia, embora no seu discurso as frases fossem na negativa: não mentir, não roubar, igual ao respeito à integridade física do outro: não agredir, não brigar. Nesse caso houve uma contradição, pois o brigar era visto ora como necessário para se defender, ora como o início de um comportamento violento a ser erradicado. O trabalho também é um valor, culminando todas as expectativas dos pais. A obediência incondicional, entretanto, era a base sobre a qual os demais princípios poderiam se desenvolver nas crianças.

Verificaram-se justificativas oferecidas pelos pais às suas práticas junto aos filhos: formação do futuro adulto mediante o ensino de princípios (como obediência, respeito aos mais velhos, justiça e respeito à vida) e hábitos sociais; expressão de carinho, proteção e atenção, cuidados com higiene e saúde, e também atenção ao acompanhamento escolar, ao cuidado com as companhias e às punições. Estas carregam sentimentos positivos como, bater para cuidar, que então não entra em contradição com o carinho; tratar firme não significa não gostar: "Eu bato 


\section{Heloisa Szymanski}

com dó por dentro, porque ela é uma menina que ajuda também”. Há diferença entre o bater disciplinador e o mero espancamento, o primeiro tem o sentido de evitar a instalação de comportamentos desviantes, e o segundo é só por raiva.

Os estados de ânimo, que também fazem parte dessa constelação, referem-se às expressões de sentimentos e disposições na implementação das práticas educativas. A punição vem sempre acompanhada de expressões de medo de que o comportamento se instale e evolua para algo pior; também apareceu como fator intensificador de práticas violentas a proteção física da criança no ambiente hostil em que vivia. Em certos momentos apareceu apreensão frente à impossibilidade de conter a raiva na desobediência ou enfrentamento da criança. Falou-se em dó diante do "dever" de punir fisicamente o filho, quer por decisão própria, quer para “dar satisfações” à vizinhança. Firmeza, dureza foram expressões frequentes no desempenho da função educativa, associadas ao dever de ter autoridade. O gostar (“crio com amor") esteve associado aos bons cuidados, incluindo ou não o contato físico. Observou-se certo desamparo e solidão frente à baixa qualidade ou falta de serviços oferecidos pelo estado: escolas, creches, educação infantil, segurança.

\section{Discussão e Considerações Finais}

Apareceram, na análise, aspectos variados do processo identitário e de socialização das crianças dessas famílias, no sentido de formar pessoas saudáveis, com profissão, autonomia econômica, e presença na sociedade. A expressão "ser alguém na vida", surgiu várias vezes no discurso das famílias, sendo interpretada como desejo de ser presente, com reconhecimento pelo outro, denotando caráter reflexivo e de pertencimento da constituição da identidade, de desejo de inclusão em um mundo cujo acesso não lhes é facilitado.

A forma de inclusão foi indicada pelo que as práticas valorizavam: obediência, submissão à autoridade, medo do superior. Pode-se supor que são os ingredientes para a constituição de ser subalterno: uma presença controlada pelo medo e ameaça e mantida dentro de uma estrutura de poder autoritária. Esses dados confirmam pesquisas anteriores
(Bernard-Peyron \& Allès-Jardel, 2002; Black \& Krishnakumar, 1998; Bouchard, 1988; McLoyd, 1990, 1998; Nunes, 1994), que atestam o predomínio de práticas educativas violentas entre pais de baixa renda e escolaridade. O presente estudo aponta para o sentido socializador das mesmas, isto é, formar pessoas dóceis à ordem autoritária.

Ao se considerar a disposição afetiva das mães, era principalmente o medo que as fazia agir e pensar, o receio de ter seus filhos cooptados pelo crime uma possibilidade muito presente onde viviam. Para elas, um filho dócil e com medo das punições estaria a salvo do crime, seria um cidadão trabalhador, adaptado e obediente às ordens da sociedade. Esse era o sentido do agir, imposto como regra de conduta (Berger \& Luckmann, 2004)

Pode-se observar que a socialização preconizada pelas famílias dirigia-se prioritariamente para o evitar a delinqüência, mais do que para a formação de pessoas reflexivas, autônomas, críticas, responsáveis por suas escolhas e com disposição de "ser mais", como diz Paulo Freire (1970, p.74). Considera-se que a socialização, movida pelo evitar oferece um contexto de constituição do que se chamou de identidade "negativa": o que os move com força especial é que os filhos não sejam delinqüentes.

O papel primordial da regra de respeito aos mais velhos era o valor à autoridade, só que num sentido autoritário, pois a horizontalidade nas trocas intersubjetivas era interpretada como ameaça à ordem, e a reação dos adultos era de indignação. A proposta dialógica de educação familiar era percebida como tentativa de retirar a autoridade parental, e a crítica à violência dela, era vista como ameaçando o poder e competência das famílias.

A adesão a crenças e valores associados a papéis desempenhados, em uma instituição como a família, assumiu um caráter identitário, de difícil transformação, contendo tanto um lugar social, como trocas intersubjetivas intrafamiliares. Para a formação da criança naquela direção, a relação oferecida pelo adulto incluiu tanto a valorização da abnegação, do interesse, da preocupação e da paciência, como a aceitação da irritação, raiva, indignação pelo desrespeito à autoridade dos pais e questionamento de seu 
poder. Há reconhecimento da responsabilidade familiar pela tarefa de socialização, coerente com um sistema de crenças e valores. A presença quase exclusiva das mulheres indicou como o papel de educadora era assumido pelas mães, que se escudavam na autoridade masculina refratária a mudanças, para implementação de seus métodos educacionais.

\section{Referências}

Berger, P. I. \& Luckmann, T. (2004). Modernidade, Pluralismo e crise de sentido. Petrópolis: Vozes.

Bernard-Peyron V. \& Allès-Jardel., M. (2002). Pratiques Éducatives, attentes parentales e style de socialization des jeunes enfants. La revue internationale de l'Éducation Familiale , v. 6, n.2, 5-31.

Black, M. M. \& Krishnakumar, A. (1998). Children in Low Income, Urban Settings: Interventions to promote mental health and well being. American Psychologist, v. 53, n. 6, 635-646.

Bouissou, C. (2001). Dynamique éducative familiale e construction identitaire de lénfant. La revue internationale de l'Éducation Familiale, v 5, n. 2, 43-61.

Bouchard, J. M. (1988). "De l'institution a la Communauté. Les Parents et les Professionnels: une rélation que se construit”. In P. Durning (Ed.), Éducation Familiale: um panorama dês recherches internationales. (pp. 157-184). Vigneux: Matrice.

Bruner, J. (1997). Atos de Significação. Porto Alegre: Artes Médicas.

Bugental, D. B; Ellerson, P. C.; Rainey, B; Lin, E. K. \& Kokotovic A. A. (2002). Cognitive Approach to Child Abuse Prevention. Journal of Family Psychology, v. 16, n. 3, 243-258.

Chambers, R. (1997). Whose reality really counts? Putting the first last. London: CTP.
Cohen, A. P. (1995). The Symbolic Construction of Community. New York: Routledge.

Critelli, D. M. (1996). Analítica do sentido:uma aproximação e interpretação do real de orientação fenomenológica. São Paulo: Brasiliense.

Daggett, J; O’Brien, M.; Zanolli, K. \& Peyton, V. (2000). Parent's Attitudes about Children: associations with parental life stories and child rearing quality. Journal of Family Psychology, v. 14, n. 2, 187-199.

Durning, P. (1999). Éducation Familiale: acteurs, processus et enjeux. Paris: PUF.

Dubost, J. (1988). La question de la spécifité des recherches-action selon les champs”. In M. A. Hugon \& C. Sebel (Eds.), Recherches impliqués, Recherches action: le cas de l"education. (pp. 4445) Bruxelles: DeBoeck.

Fortin A., Chamberland C. \& Lachance L. (2000).La Justitication de la violence envers l'enfant: um facteur de risque de violence. La Revue Internationale de l'Éducation Familiale, v. 4, n. 2, 5-34.

Freire, P. (1970). Pedagogia do Oprimido. Rio de Janeiro, Paz e Terra.

Freire, P. (1980). Conscientização. São Paulo: Moraes.

Freire, P. (1981). "Criando métodos de pesquisa alternativa”. Em C. R. Brandão (Org.), Pesquisa Participante. São Paulo: Brasiliense.

Freire, P. (1996). Pedagogia da Autonomia. Rio de Janeiro. Paz e Terra.

Freire, P. (1994). Pedagogia da Esperança. Rio de Janeiro. Paz e Terra.

Giddens, A.(1991). Modernity and SelfIdentity. Oxford: Blackwell Publishers. 
Giorgi, A.(1985). Phenomenology and Psychological Research. Pittsburg: Duquesne University Press.

Glaser, B. G. \& Strauss, A. L. (1967). The Discovery of Grounded Theory. New York:Aldine

Heidegger, M. (1981). Todos Nós...Ninguém: um enfoque fenomenológico do Social. São Paulo: Moraes.

Heidegger, M. (1988). Ser e Tempo. Petrópolis: Vozes.

Holstein J. A. \& Gubrium J. (1995). The Active Interview. London: Sage.

McLoyd V. C. (1990). The Impact of Economic Hardship on Black Families and Children: psychological distress, parenting and socioemotional development. Child Development, 61, p. 311-346.

McLoyd V. C. (1998). Social Economical Disadvantage and Child Development. American Psychologist, v. 53, n. 2, 185-204.

Nunes, T. (1994). O Ambiente da Criança. Cadernos de Pesquisa, n.89, p. 5-24.

Ricoeur, P.(1991). O Si Mesmo Como um Outro. Campinas: Papirus.

Szymanski, H. (2001). A relação Família Escola: Desafios e Perspectivas. Brasília: Editora Plano.

Szymanski, H. (2002). A Entrevista na Pesquisa em Educação: a prática reflexiva. Brasília: Editora Plano.

Szymanski, H. (2004). A Prática Reflexiva com Famílias de Baixa Renda. Anais do II Seminário Internacional de Pesquisa e estudos Qualitativos. Bauru:SEPQ.

Thiollent, M. (1992). Metodologia da Pesquisa-Ação. São Paulo: Cortez.

Tornaria, M. L. G., Vandenmeulebroeke, L \& Colpin, H. (2001). Pedagogia Familiar. Montevideo: Editora Trilce.
Agradecimento aos alunos participantes do curso "A relação família/creche e a constituição da identidade”, PEPG em Educação: Psicologia da Educação PUC-SP.

\section{Apoio CNPq}

